\title{
Psychological distress in mothers of infants admitted in neonatal intensive care unit (NICU)
}

\author{
Niranjan $\mathrm{HS}^{1}$, Nijaguna $\mathrm{A}^{2}$, Jagadish $\mathrm{AS}^{3}$, Naveen Benakappa ${ }^{4}$ \\ ${ }^{1}$ Dr Niranjan HS, Associate Professor, Department of Pediatrics, ${ }^{2}$ Dr Nijaguna A Associate Professor, Department of \\ Pediatrics, ${ }^{3}$ Dr Jagadish AS, Senior resident, Department of Pediatrics, ${ }^{4}$ Dr Naveen Benakappa, Head, Department of \\ Neonatology, Neonatology. All are affiliated with Indira Gandhi Institute of Child Health,South hospital complex \\ Dhrmaram post Bangalore, Karnataka, India
}

Address for correspondence: Dr Jagadish A S, Email: drjagusomanna@ yahoo.com

\begin{abstract}
Introduction: Mothers whose infants are admitted to NICU undergo significant distress which can interfere with mother infant bonding. Materials \& Methods: Mothers belonging to two groups: Group 1 -(clinical) 30 mothers of infants admitted in NICU of IGICH. Group 2-( control) 30 mothers of normal infants from Jayanagar General Hospital (JGH) were included. Period Of Study: July 14 to Dec 14. All mothers cooperative for interview, mothers from intact families were included. Mothers of infants having major illness or development delay were excluded. Results: Qualitative analysis of clinical sample indicates $90 \%$ mothers in "extremely stressful" severity rating and $10 \%$ "very stressful" rating. Urban families experience more stress $(\mathrm{p}=0.012)$. Previous NICU experience showed higher stress levels as compared to no previous experience $(\mathrm{p}=0.052)$. Coping styles like praying to god about infant well being $(100 \%)$, reading books(26\%), always thinking about baby(100\%), expressing emotions to husband and families (85\%), blaming themselves(56\%) and others like in laws(10\%), meditating(12\%), keeping feelings and emotions to themselves (43\%), sitting and crying(10\%). control group used praying and talking to themselves (43\%), sitting and crying (10\%). Control group used praying and talking to family and coped better. Statistically significant difference indicating higher distress in mothers of clinical group. $100 \%$ felt bad, lonely, hurt and sad 50\% felt hopeless about future and $25 \%$ expressed anger mostly directed towards their mother/husband. $70 \%$ mothers in clinical group were not allowed to breastfeed their causing emotional distress to the mother. Conclusion: Mothers are at immense stress when separated from their infants hence measures to reduce the same must be considered.
\end{abstract}

Keywords: Parental Stressor Scale: Neonatal Intensive Care Unit (PSS:NICU), General Health Quesstionnaire-28(GHQ28), copying styles.

\section{Introduction}

Mother infant bonding is a rapid process which occurs immediately after birth, in which mother forms an affectionate attachment with the infant. This is interrupted when baby is immediately admitted to NICU [1]. Process of having a baby is widely regarded as a life crisis \& it is much more so if the infants are born premature or are low birth weight or is critically ill requiring NICU care [2]. Long periods of hospitalization \& isolation from the parents frequently disturb the social interaction \& prevent family integration. In addition, many parents experience times of uncertainty over psychosocial aspects in these mothers.

Manuscript received: $10^{\text {th }}$ Nov 2015

Reviewed: $25^{\text {th }}$ Nov 2015

Author Corrected: $6^{\text {th }}$ Dec 2015

Accepted for Publication: $14^{\text {th }}$ Dec 2015
Similarly during their stay in the NICU a number of families may experience times of uncertainty over the survival of infants which subsequently manifest feelings of stress, guilt and concerns of inability to cope and interfere with process of transition to home life after discharge from hospital.

Parental attitudes, which are important influences in the development of child's personality, are disturbed during NICU stay and may lead to chronic disturbances in the mother-child early bonding \& later relationship [3]. Various studies have shown high stress levels in the mother of infants admitted in NICU. This study aims at understanding the stress, coping styles and other psychological aspects in these mothers. 


\section{Materials and Methods}

This case control study was conducted in the NICU of a tertiary care teaching hospital and postnatal ward of a general hospital including 30 mothers of infants in NICU of IGICH as clinical group 1 and 30 mothers of normal infants from general hospital forming control group 2. Study was conducted between July 14 to Dec 14. Written informed consent was taken from all the mothers. Mothers who scored high on PSS: NICU scale were offered professional help. All interviews were done by the same investigator. All mothers cooperative for the interview and ones from intact families were included .Mothers with major illnesses were excluded. Following tools were used.

1. Socio-demographic data sheet: A semi structured interview to obtain information regarding the mothers \&infants was conducted and results documented in prepared proforma. Bonding between mother and infants and social support available was assessed with help of questions in the interview schedule.

2. Parental Stressor Scale: Neonatal Intensive Care Unit (PSS:NICU [4]: Developed to measure parental perception of stressors arising from the physical and psychosocial environment of the NICU. 34 questions which included four dimensions, sights and sounds of the unit, infant behavior and appearance, staff relationships and parental role alteration were put to the parents and were asked to rate the level of stress engendered by the items on a 5 point Likert type scale ranging from " 1 " not at all stressful to " 5 " extremely stressful. Severity of stress was calculated based on the sum of total of responses on all the items.0-34: not at all stressful, 35-68:little stressful, 69-102:moderately stressful,103-136: very stressful, 137-170: extremely stressful.

3. Interview schedule: For the assessment of social support, mothers coping in general and specific areas related to pregnancy, child birth, bonding and lactation .It also had questions related to information that the mother had in NICU.

4. General Health Questionnaire-28(GHQ-28) (Goldberg and Hillier, 1972) [5]:A measure of current mental health status. It consists of 28 items used as screening tool for detection of psychiatric and non psychiatric illness. Assess somatic symptoms, anxiety and insomnia, social dysfunction and severe depression. The scale asks whether the respondent has experienced a particular symptoms or behavior recently. Each item is rated on a four point scale(less than usual, no more than usual, rather more than usual or much more than usual).

Statistical Analysis: The socio demographic data and clinical characteristics of the clinical group including stress on the PSS: NICU were studied using frequencies and percentages. Correlations were done between the sub scales of the PSWSW: NICU scale and also between the GHQ scores of the study and control groups using t-tests and one way ANOVA.

\section{Results}

Socio- demographic and clinical characteristics of the clinical and control groups: taken as mothers characteristics age, education, occupation, domicile, income), information about the birth parity, antenatal complications, type of delivery, pregnancy loss and infant characteristics (age, sex) showed no significant difference among the two groups.

Diagnostic distribution of the infants in NICU group sepsis (33.3\%), preterm (26.7\%), respiratory distress syndrome(16.7\%), hyperbilirubinemia (13.3\%) and etc.

Table 1: PSS: NICU scores for the clinical group

\begin{tabular}{|c|c|c|}
\hline & Mean & Standard Deviation \\
\hline Sights and sounds of the unit & 27.40 & 1.61 \\
\hline Baby looks and behavior & 73.63 & 6.49 \\
\hline Parental role and relationships & 47.07 & 10.30 \\
\hline Total score & 148.43 & 10.30 \\
\hline
\end{tabular}

Mean scores on the three sub scales and the total score on PSS:NICU are given in the above table. All the sub scales on the PSS: NICU correlated significantly with the total score. 
Table 2 PSS: NICU scale severity rating of the clinical group

\begin{tabular}{|c|c|c|}
\hline Severity rating & Number & Percentage \\
\hline Extremely stressful (137-170) & 27 & 10 \\
\hline Very successful(103-136) & 3 & 0 \\
\hline Moderately stressful(69-102) & 0 & 0 \\
\hline Little stressful(35-68) & 0 & 0 \\
\hline Not at all stressful(0-34) & 0 & 0 \\
\hline
\end{tabular}

Above table shows majority (90\%) as being extremely stressful and $10 \%$ very stressful.

Table 3: Correlation of PSS: NICU and GHQ-28 scores of the clinical group

\begin{tabular}{|c|c|c|c|c|c|c|}
\hline Score & N & Mean & SD & t-test & df & P \\
\hline PSS:NICU & 30 & 148.43 & 10.30 & 63.508 & 29 & 0.000 \\
\hline GHQ & 30 & 11.63 & 3.73 & & & \\
\hline
\end{tabular}

When the GHQ-28 scores of both the groups were compared using paired t-test, the difference was found to be significant.

Table 4: Correlation of GHQ-28 scores of the clinical and control group

\begin{tabular}{|c|c|c|c|c|c|c|}
\hline Score & $\mathrm{N}$ & Mean & SD & t-test & df & P \\
\hline GHQ(clinical) & 30 & 11.63 & 3.73 & 11.878 & 29 & 0.000 \\
\hline GHQ(control) & 30 & 3.13 & 1.78 & & & \\
\hline
\end{tabular}

Correlation between the two groups was significant.

Table 5: Comparison of GHQ-28 scores between the clinical and control group

\begin{tabular}{|c|c|c|}
\hline GHQ score & group & Control (n,\%) \\
\hline & Clinical (n,\%) & $5(16.7)$ \\
\hline Above cut off & $30(100)$ & $25(83.3)$ \\
\hline Below cut off & $0(0)$ & \\
\hline
\end{tabular}

Table 6: One way ANOVA between different variables education, income, occupation, parity, type of delivery ,previous pregnancy loss, NICU intervention) and PSS: NICU scores of the clinical group did not show any statistically significant difference except domicile status which showed the urban families experienced significantly more stress.

\begin{tabular}{|c|c|c|c|c|c|c|}
\hline Domicile & N & Mean & SD & Df & F & P \\
\hline urban & 21 & 151.43 & 8.72 & 1 & 7.179 & 0.012 \\
\hline Rural & 9 & 141.44 & 10.78 & & & \\
\hline
\end{tabular}

Table 7: Independent sample t-tests done between different variables and PSS:NICU scores when the means were compared between previous NICU experience and PSS:NICU scores

\begin{tabular}{|c|c|c|c|c|c|c|}
\hline $\begin{array}{c}\text { Previous NICU } \\
\text { experience }\end{array}$ & N & Mean & SD & Df & T & P \\
\hline present & 3 & 159.33 & 3.06 & 28 & 2.034 & 0.052 \\
\hline absent & 27 & 147.22 & 10.12 & & & \\
\hline
\end{tabular}




\section{Discussion}

Aspects of parental role, such as not being able to protect the baby, and separation and the appearance and behavior of the sick infant cause significant distress in parents whose sick infant is hospitalized in NICU.

Twenty seven (90\%) mothers scored more than 137 on the PSS: NICU falling into the "Extremely stressful" severity rating of PSS:NICU and three mothers (10\%)scored between 103-136 indicating "very stressful" states according to PSS:NICU. This is similar to the study of Blumberg [6] and Miles [7] which indicated high stress levels in mothers of infants in NICU especially in the initial period [8].

There was a positive statistically significant correlation between the PSS :NICU Total score and GHQ-28 score of the clinical group $(\mathrm{p}=0.000)$.PSS is a measure of the stress experienced and GHQ-28 is a screening tool for non psychotic psychiatric illness with items on anxiety, depression and somatic complaints which was reported by the mothers in the clinical sample indicating high level of psychological distress .Similar results were seen in studies that have looked at symptoms of anxiety, post traumatic stress symptoms and depressive symptoms in mothers of infants in NICU,[10]).

There was statistically significant difference between the GHQ-28 score of the clinical group and the control group $(\mathrm{p}=0.000)$.This indicates the psychological distress in mothers of infants in the NICU is significantly higher compared to mothers with normal infants reiterating findings from previous studies.

It was found that all the 30 mothers from the clinical group scored above the cut off on the GHQ-28 and 5 mothers in the control group scored above the cut off score. Since many items on the GHQ-28 are for symptoms since normal pregnancy and delivery is also considered to be very stressful [11].

In the clinical group most of the mothers indicated anxiety, depressive features and sleep disturbances being more when compared to somatic complaints.

Statistically significant positive correlation was found between all the three subscales of PSS:NICU and total score. This suggests that the sights and sounds in the NICU because of all the technical equipment and the infants looks and behavior along with the role strain on the mothers seen as being extremely stressful in $90 \%$ of the mothers. This is in keeping with several studies done which have looked at the independent contribution of various factors in NICU.[4,9]

There was statistically significance between domicile status and PSS:NICU score indicating that the families from urban area experienced significantly higher stress which is in keeping with some studies by Lau and Morse [3]. It is possible that urban families had more stress in NICU because of poor social support. However there urban families had more stress in NICU because of poor social support. However there was no correlation between the domicile status and the GHQ28 score indicating no influence on the psychological distress.

Mothers with previous NICU experience reported significantly higher stress levels. This was not surprising since prior exposure could have acted as a traumatic event and the subsequent exposure caused reexperiencing and arousal symptoms with anxiety along with anticipatory anxiety as seen in post traumatic stress disorders. However one needs to re-examine this finding further in the light of the small sample size and only three mothers having prior NICU exposure in the clinical group.

Mothers used coping mechanism like praying to god for strength and infants well being(100\%),reading books(26\%),expressing emotions to family members and husbands, blaming themselves for the baby's situation (56.66\%), blaming others (10\%), speaking to others in the ward to distract themselves $(56.66 \%)$,not expressing emotions to anybody (43.33\%),expressing anger and sadness towards their mothers $(26.22 \%)$,towards their husbands (10\%),sitting and crying (13\%).

Mothers of infants in NICU reported that missed having close contact with infants. It was found that very few mothers kept coming to the NICU to stand and peep at the baby, thus mother (70\%) were not allowed to feed the baby which made them feel bad and hurt, and also resulted in perceived breast milk insufficiency. Majority would express milk and throw it which was very painful.

Limitations of the study: .Small sample size, there was no adequate follow up, Ideal method of observing mother-infants bonding by using video recordings could not be done in this study and fathers were not included when the stress levels were studied. 


\section{Conclusion}

Psychological distress in mothers admitted to NICU plays important role in the overall development of newborn. This study adds to the fact that mothers are at immense stress when separated from their infants. This study recommends to provide family centered care to increase awareness among the family members and involve all in care taking. NICU environment to be made more mother friendly and allow stimulation program for infants in NICU like touch by mother [12] which facilitates mother infants interaction. It is recommended to have support group for mothers to facilitate management of stress and plan for individualized program for providing support, discussing status of the infants in NICU. Pre discharge counseling to be done in detail. Availability of mental health professional in the general pediatric setting would be beneficial

\section{References}

1. BRAZELTON TB. THE EARLY MOTHERINFANT ADJUSTMENT.

Pediatrics. 1963 Nov;32:931-7.

2. Siegel, R., Gardner, S.L, \&Merenstein, G.B. Families in crisis: Theoretical and practical considerations.In:Merenstein,G.B. \& Gardner, S.L. eds.Handbook of Neonatal Intensive Care. London:Mosby Yearbook. 1993;431-432

3. Miles MS, Funk SG, Carlson J. Parental Stressor Scale: neonatal intensive care unit. Nurs Res. 1993 May-Jun;42(3):148-52.
4. Goldberg DP, Hillier VF. A scaled version of the General Health Questionnaire. Psychol Med. 1979 Feb;9(1):139-45.

5. Blumberg NL. Effects of neonatal risk, maternal attitude, and cognitive style on early postpartum adjustment. J Abnorm Psychol. 1980 Apr;89(2):139-50.

6. Miles, M.Assessing parental stress in intensive care units.American journal of maternal and child nursing. 1983;8:345-359.

7. Singer LT, Salvator A, Guo S, Collin M, Lilien L, Baley J. Maternal psychological distress and parenting stress after the birth of a very low-birthweight infant. JAMA. 1999 Mar 3;281(9):799-805.

8. Padden, T., and Glenn, S.Maternal experience of preterm birth and neonatal intensive care.Journal of reproductive and infant psychology.1997;15:121-139.

9. Holditch-Davis D, Bartlett TR, Blickman AL, Miles MS. Posttraumatic stress symptoms in mothers of premature infants. J Obstet Gynecol Neonatal Nurs. 2003 Mar-Apr;32(2):161-71.

10. SHAINESS N. THE PSYCHOLOGIC EXPERIENCE OF LABOR. N Y State J Med. 1963 Oct 15;63:2923-32.

11. Field TM, Schanberg SM, Scafidi F, Bauer CR, Vega-Lahr N, Garcia R, Nystrom J, Kuhn CM. Tactile/kinesthetic stimulation effects on preterm neonates. Pediatrics. 1986 May;77(5):654-8.

\section{How to cite this article?}

Niranjan HS, Nijaguna A, Jagadish AS, Naveen Benakappa. Psychological distress in mothers of infants admitted in neonatal intensive care unit (NICU). Pediatr Rev: Int J Pediatr Res 2015;2(4):125-129.doi:10.17511/ijpr.2015.i04.16 